\title{
Golpe de Estado o Sucesión Constitucional en Honduras 2009
}

\begin{abstract}
Sahira Karine Núñez Moncada
Profesora Investigadora. Máster en Derecho Mercantil.

Instituto de Investigación Jurídica, Universidad Nacional Autónoma de Honduras
\end{abstract}

\section{RESUMEN}

Lo acontecido en Honduras en su crisis política, ha generado múltiples posturas, el objetivo del presente trabajo es identificar en base a la Constitución de Honduras, otras leyes y la doctrina si lo sucedido en Honduras fue un Golpe de Estado o una Sucesión Constitucional.

Después de realizar la investigación de tipo Jurídico-descriptivo, se llegó a la conclusión, que lo acontecido en el 2009 en Honduras fue un Golpe de Estado.

\section{ABSTRACT}

What happened in Honduras as a political crisis has led to multiple positions, the objective of this study is to identify, based on the Constitution of Honduras, other laws and the doctrine, whether what happened in Honduras was a coup or a constitutional succession.

After conducting research of a Legaldescriptive type, we came to the conclusion that what happened in 2009 in Honduras was a coup.

Palabras clave: Golpe de Estado, Keywords: Strike of State, Coup d'état, Sucesión constitucional, Honduras, Constitutional Succession, Honduras, Constitución.

Constitution. 


\section{INTRODUCCIÓN}

Cada nación tiene su historia, y por más que hoy, muchas de ellas sean extremadamente poderosas, seguramente han pasado por algún episodio dramático; guerras, enfermedades, terrorismo, catástrofes, etc. Honduras, nuestro país no es la excepción y en el 2009 ha enfrentado una de sus peores crisis políticas que trascendió las fronteras al punto que la Organización de Estados Americanos, la Comunidad Europea y otros de la comunidad internacional han condenado lo que todos ellos denominan "Golpe de Estado en Honduras". Como resultado, la Organización de Estados Americanos (OEA) separo a Honduras de ese mismo organismo, tal como hizo con Cuba hace 47 años.

Por otra parte están los que establecen que fue una Sucesión Constitucional, con base en improbar la conducta del Presidente Manuel Zelaya por las reiteradas violaciones que según ellos, sufrió la Constitución y las leyes, así como por la inobservancia de las resoluciones y sentencias de los órganos jurisdiccionales por parte de este. Cabe entonces preguntarse con base en la Constitución de Honduras y otras leyes si ¿Lo sucedido fue un Golpe de Estado o una Sucesión Constitucional?, ya que todos tienen una postura respecto a este asunto. Sin embargo, es menester indagar en este juicio, porque no todos comparten la misma visión.

Trataré entonces de identificar qué es lo que se entiende por Golpe de Estado y por Sucesión Constitucional realizando una investigación de tipo Jurídico-descriptivo, es decir aplicando de manera pura el método analítico en estos dos conceptos, descomponiéndolos en tantas partes como sea posible, para así poder Ilegar a las conclusiones pertinentes.

\section{I.- ANTECEDENTES HISTÓRICOS DEL CONCEPTO GOLPE DE ESTADO}

La designación castellana de golpe de Estado es traducción de la expresión francesa de Coup d'Etat y de acuerdo a su real contenido quizá fuera más exacto decir Golpe al Estado o al Poder. En la terminología alemana se emplea la gráfica expresión de Putsch.

El concepto Golpe de Estado (Coup d'État) comenzó a ser empleado en Francia en el siglo XVIII, para referirse a una serie de medidas violentas y repentinas tomadas 
por el Rey, sin respetar la legislación ni las normas morales, generalmente para deshacerse de sus enemigos, cuando el Rey mismo consideraba que eran necesarias para mantener la seguridad del Estado o el bien común. En este sentido original, el concepto era muy similar a lo que se denomina en la actualidad "autogolpe", es decir el desplazamiento de ciertas autoridades del Estado, por parte de la autoridad suprema.

El término se fue ampliando a lo largo del siglo XIX para significar la acción violenta de un componente del Estado, por ejemplo, las fuerzas armadas, con el fin de desplazar a la cabeza del mismo. El concepto se superpuso entonces, y a la vez se diferenció, del de "revolución", caracterizado sobre todo por estar principalmente organizado por civiles ajenos al Estado.

Ya en el siglo XX, en 1930 apareció el libro Técnica del Colpo di Stato (Técnica del Golpe de Estado) de Curzio Malaparte, que impondría el uso generalizado del concepto, básicamente en su acepción moderna, a partir del análisis crítico de las acciones del fascismo y el nazismo.

Malaparte aplica el concepto del Golpe de Estado no sólo a una operación ejecutada por integrantes del Estado, sino también por poderes civiles, que mediante la desestabilización del gobierno a través de acciones orientadas a generar caos social, provocan su caída y acceden al poder. Para Malaparte, la diferencia sustancial del concepto de Golpe de Estado con los de "guerra civil" y "revolución" es esencialmente el uso de la sorpresa y la escasa duración relativa de las operaciones, reduciendo al mínimo el tamaño y la intensidad de la confrontación armada.

En 1962, Samuel Finer escribió otro libro importante para la conceptualización del Golpe de Estado: "The Man on Horseback: The Role of the Military in Politics" (tit. trad. Los militares en la política mundial). La edición original de Finner fue ampliada en 1975 (Peregrine Books) y en 1976 (Penguin Books); en 1988 se realizó también una edición publicada por Westview Press. Finner, pensando en los militares, distingue cuatro niveles de presión sobre el Estado, de los cuales considera legítimo sólo al primero:

1) Presión sobre el gobierno o el congreso, para influir a favor de sus intereses;

2) Reclamos al gobierno o al congreso bajo aviso de que, en caso de no ser 
aceptados, procederán a realizar acciones dañinas. Finner considera este nivel como extorsión ilegítima. Aun sin que el gobierno cambie, Finner sostiene que esta situación podría dar lugar a un "Golpe de Estado Tácito", en la que el gobernante toma las decisiones que le impone el grupo de presión.

3) Uso de la violencia o amenaza de violencia para reemplazar al gobierno civil, por otro gobierno civil.

4) Uso de la violencia o amenaza de violencia para reemplazar al gobierno civil, por un gobierno militar.

En el curso del siglo XX, el Golpe de Estado adoptó la forma típica de una acción de las Fuerzas Armadas desplazando por la fuerza al gobierno establecido. Sin embargo, sobre todo a partir del colapso de las dictaduras latinoamericanas, en la década de 1980, los golpes de Estado han ido adoptando formas más complejas y menos evidentes, mediante técnicas de desestabilización económica ("golpes de mercado") y generación de climas de caos social (saqueos, huelgas, etc.), que pueden ser agudizados mediante el uso de medios de comunicación de masas.

\section{II.- LA NATURALEZA JURÍDICA DEL GOLPE DE ESTADO}

La naturaleza y frecuencia de Golpes de Estado ha variado tanto por país y por el contexto. América Latina tiene la mayor experiencia de la participación e intervención militar, que data casi desde el inicio de las Repúblicas, e incluso que afectan a los estados relativamente avanzados como Brasil, Chile y Argentina. Hay varias escuelas distintas pero relacionadas de pensamiento acerca de Golpes de Estado y sus causas. Algunos tratan de explicarlo en gran parte; como una respuesta a la agitación social, el colapso económico y político y al fracaso institucional. En vista de que la intervención ha sido generalmente una respuesta militar al malestar social y político en las sociedades donde el nivel de cultura política es pequeño o mínimo. Es dudoso que un fenómeno tan complejo y variable se pueda explicar en términos de una o un pequeño número de variables.

Paradójicamente, el Golpe de Estado, a diferencia del concepto Democracia puede definirse técnicamente; según el diccionario de la Real Academia Española, como: " una medida grave y violenta por la cual se toman los poderes del Estado, usurpando las atribuciones de otro".

En una definición más corta y concisa, podríamos decirque es una usurpación 
violenta e ilegal del poder de un país por parte de un grupo; si nos adentramos en temas legales, podemos afirmar que esta acción viola y vulnera la legalidad institucional vigente en un país. Este golpe se lleva a cabo por un grupo de individuos que pretenden derrocar o sustituir al régimen existente utilizando la fuerza; el fin es sustituirlo por otro que está organizado por dicho individuos.

Un Estado democrático se caracteriza por la división de poderes; ejecutivo, legislativo, judicial. El cambio de Gobierno, en los países democráticos, se realiza normalmente mediante elecciones competitivas, que no son sino un modo de renovación periódica del equipo gobernante. El Golpe de Estado es también un procedimiento para cambiar de Gobierno, pero, a diferencia de aquéllas, es ilegal y suele ir acompañado de violencia. Es Ilevado a cabo por una persona o minoría de ellas perfectamente organizada que actúa de acuerdo a un plan trazado previamente con minuciosidad, con rapidez y eficacia para lograr el fin perseguido. Los regímenes que se instauran como consecuencia del uso del Golpe son normalmente autocráticos y fuertes, y se ven condicionados por la lógica interna del procedimiento utilizado para acceder al poder, por lo que, para mantenerse en el mismo y en esto estriba su debilidad, han de evitar toda medida liberalizadora que ponga en peligro su existencia ${ }^{3}$. Una característica principal de esta acción es el predomino de las Fuerzas Armadas por sobre las demás instituciones de Gobierno; el presidente es nombrado por los jefes de dichas fuerzas o por poderes aliados que han intervenido en el Golpe.

\section{III.- CONCEPTOS DE GOLPE DE ESTADO}

Aristóteles, en la POLÍTICA, LIBRO VIII, distingue dos tipos de revolución, la revolución propiamente dicha y el Golpe de Estado. Define acertadamente la naturaleza de ambas y refiriéndose al Golpe de Estado dice "Otras veces no es el alzamiento contra la forma de gobierno establecida, sino que se consiente en dejarla substituir, pues los descontentos, lo que quieren, es gobernar ellos mismos....". Si bien Aristóteles no emplea la palabra golpe de Estado, da su principal característica; el apoderamiento del gobierno con la expulsión de aquellos que, legítimamente son titulares del poder ${ }^{4}$.

3 Canal Social. Enciclopedia. Política. - http://www.canalsocial.net/enciclopedia/enciclopedia.asp - S. Sánchez González. Cortesía de Editorial Rialp. Gran Enciclopedia Rialp, 1991.

4 "Golpe de Estado" Enciclopedia Jurídica Omeba, Tomo XII. Buenos Aires. Argentina. 1986. Pag. 350 
El Golpe de Estado es un acto de autoridad consistente en un atentado o ataque meditado, ilegal y brusco a las normas de organización, de funcionamiento o de competencia de las autoridades constituidas; atentado o ataque dirigido, según un plan preconcebido y por motivos diversos, por un hombre o grupo de hombres asociados con el fin de: o apoderarse del poder, o de defender o reforzar su posición en el mismo (o sea, en el gobierno), o de producir una modificación en la orientación política del país.

El filósofo español Ortega y Gasset caracteriza el Golpe de Estado de la siguiente manera: "No todo proceso de violencia contra el poder público es revolución. No lo es, por ejemplo, que una parte de la sociedad se rebele violentamente y los sustituya con otros. Las convulsiones de los pueblos americanos son casi siempre de este tipo"

R. M. Maclver en su libro The web of government, citado por Linares Quintana, define en forma contradictoria y confusa el fenómeno de la revolución. Y al tratar el tema que nos ocupa dice: "El nombre de revolución puede tener conexión con varias clases de Coup d'Etat o Putsch, por lo menos cuando triunfan, aun cuando no hagan más que transferir las riendas del gobierno de un grupo de usurpadores del poder a otro similar que procura obtenerlo. De esta clase son las revoluciones de palacio y las numerosas revoluciones de América Latina, que sacan a un dictador para poner a otro, sin ninguna consecuencia importante en la forma o en la política del Estado ${ }^{6 "}$.

Para los americanos dice Sánchez Viamorte cuando hablan de revolución se refieren siempre a conmociones de carácter popular, convertidas en insurrecciones a mano armada, o en Golpes de Estado que consisten en el apoderamiento del poder como fruto de un motín militar. Y agrega que, en el Golpe de Estado sólo hay cambio de personas, de funcionarios y el orden jurídico institucional permanece intacto. Con relación al poder constituyente no ha pasado nada. Y más adelante, en una nota, dice “...la expresión Golpe de Estado se está usando con una acepción más amplia y abarca cualquier clase de conmoción capaz de derribar a las autoridades constituidas o derrocar a los gobernantes sustituyéndolos por otros en el ejercicio del poder.

\footnotetext{
${ }^{5}$ Segundo V. LInares Quintana, Tratado de la ciencia del Derecho constitucional, Buenos Aires. 1956, t. 6 pag. 254. ${ }^{6}$ ob. cit., págs. 258 y 259.
} 


\section{A.- OTRAS DEFINICIONES}

1. Medida grave y violenta que toma uno de los poderes del Estado, usurpando las atribuciones de otro ${ }^{7}$.

2. Acción de apoderarse violenta e ilegalmente del gobierno de un país alguno de los poderes del mismo, por ejemplo, el ejército ${ }^{8}$.

3. Usurpación ilegal y violenta del poder de una nación?

4. Usurpación del poder por parte de un grupo ${ }^{10}$.

5. Golpe de Estado, violación y vulneración de la legalidad institucional vigente en un Estado por parte de un grupo de personas que pretenden, mediante la fuerza, sustituir o derrocar el régimen existente, sustituyéndole por otro propicio y generalmente configurado por las propias fuerzas golpistas. Este ataque contra la soberanía implica que la mayoría de los Golpes de Estado supongan la retención de los organismos depositarios de aquélla (congresos, gobierno) o de sus miembros. Los participantes suelen tener control sobre elementos estratégicos de las Fuerzas Armadas y de la policía y, para asegurar el triunfo de su acción, intentan controlar también los medios de comunicación ${ }^{11}$.

Vemos entonces, que Golpe de Estado, es un intento de cambiar un gobierno por la amenaza o el uso de la fuerza, por lo general pero no siempre se asocia con los militares. En la mayoría de los casos se lleva a cabo el golpe de Estado para desplazar al grupo de poder en funciones y establecer el poder a un grupo alternativo.

El Golpe es a menudo un intento de poner remedio a una queja específica o inmediata y es muy poco probable que implique una modificación a gran escala en el orden social. A menudo el golpe de Estado se lleva a cabo para prevenir el cambio revolucionario desde abajo e imponer una medida de reforma desde arriba. El nuevo gobierno instalado por el Golpe de Estado por lo general se basa en un cierto grado de colaboración civil, tal vez requiera la colaboración de la

\footnotetext{
${ }^{7}$ Diccionario Ideológico de la lengua española, Julio Casares de la Real Academia Española, Editorial Gustavo Gili S.A.-Barcelona, 1985.

${ }^{8}$ Diccionario de uso del español, María Moliner, A-G, Editorial Gredos S.A. - Madrid, 1997.

${ }^{9}$ Espasa Calpe 2001.

${ }^{10}$ Diccionario Anaya de la Lengua

11 "Golpe de Estado" Enciclopedia Microsoft@ Encarta® en línea 2002 http://encarta.msn.es @ 1997-2002 Microsoft Corporation.
} 
administración pública, miembros de la clase media, grupos profesionales, políticos y partes simpatizantes como los campesinos o dirigentes sindicales, pero rara vez ofrece una solución útil a los problemas sociales y económicos a largo plazo.

\section{IV.- CARACTERÍSTICAS DEL GOLPE DE ESTADO}

El Golpe de Estado como toda manifestación socio-política cumple siempre un proceso, más o menos acentuado y distintivo. Los móviles que lo impulsan pueden abarcar una amplia gama de motivos; desde eminentemente personales, como ambiciones de poder, egoísmos, descontentos sobre la orientación y marcha de un gobierno, hasta abarcar estados espirituales inspirados en políticas de bien público o el deseo de amplios cambios en la vida jurídica política, económica o social de una nación. Los móviles estrechos del primer tipo suelen ser característicos de los Golpes de Estado Puros, los segundos más generales de tendencia dogmática e idealistas, son propios de los Golpes de Estados Incidentales o inmersos en las revoluciones. Señalamos simplemente un hecho común. El proceso se inicia siempre con una acción conspirativa, hay que buscar adeptos y sembrar el descontento público.

La etapa siguiente es el franco enfrentamiento con las autoridades constituidas; podrá ser un cabildo abierto, una sublevación o una conspiración palaciega, etcétera, casi siempre Ilevada a cabo por grupos reducidos. En esta etapa se pone en movimiento a la violencia. La parte final del proceso, consecuencia de las etapas anteriores que lo integran, consiste en la expulsión de los gobernantes, la toma del poder, es decir el Golpe de Estado en sí; a veces el proceso aparece oscurecido en las Ilamadas "conspiraciones palaciegas" realizadas desde dentro del poder mismo en las antesalas de los despachos oficiales.

Dentro de las características tenemos las siguientes:

\section{A. Expulsión de las autoridades y subsecuente toma del poder.}

La expulsión de quienes gobiernan y el subsiguiente reemplazo por quienes realizan el golpe de Estado, constituye la característica propia de esta figura.

No interesa para que exista el Golpe de Estado que las autoridades gobernantes sean legitimas o no, la generalidad de los casos de este fenómeno político, es 
como expresión de descontento, resentimiento o ambición personal, y suele Ilevarse a cabo contra las autoridades legítimamente constituidas.

Por otra parte, para que exista el Golpe de Estado, para que se lo considere consumado, es suficiente la expulsión de las autoridades gobernantes, no interesando que quiénes las reemplacen pertenezcan o no a la rebelión triunfante. Lo lógico y común, no obstante, es que los autores del golpe de Estado ocupen el gobierno. De acuerdo con lo que llevamos dicho es necesario el triunfo del movimiento sedicioso. Caso contrario si no hay expulsión de las autoridades constituidas; habrá cuando mucho, una tentativa de Golpe de Estado con el acompañamiento de la rebelión o motín que le ha dado base física.

\section{B. Violencia.}

La palabra expulsión Ileva siempre implícita la idea de violencia, ya sea esta física o moral. Sin violencia, cualquiera sea la naturaleza de ésta, no habrá golpe de Estado. En tales casos sólo habrá una entrega una transferencia o un renunciamiento del poder, eminentemente.

Por lo general la violencia que acompaña al Golpe de Estado es de naturaleza física y a veces, aunque no necesariamente, con derramamiento de sangre. No es sin embargo imprescindible que la violencia se presente como una fuerza física que actúa contra los titulares del poder y golpea a sus defensores. Puede presentarse también, aunque no es frecuente, como una poderosa fuerza cívica, moral, religiosa o patriótica que no alcanza a traducirse en hechos de violencia física y que, sin embargo, obliga a una entrega voluntaria del poder. Lo común y frecuente, por el contrario, es el Coup d'Etat con violencia física, derramamientos de sangre y choques entre fuerzas armadas. Es la lucha por el Poder entre quienes lo poseen y quienes quieren obtenerlo. A veces el periodo crucial es breve, otras degenera en la guerra civil.

En síntesis, lo que caracteriza al Golpe de Estado es la entrega forzada del Poder violentando la voluntad de quienes lo detentan y no importando si la violencia es física o moral. La violencia, cualquiera sea su naturaleza es siempre unida al Golpe de Estado, y el acto de fuerza, frecuentemente engendra nuevos actos de fuerza, motivados consecuentemente los Golpes de Estado por el impulso de odios, ambiciones o utopías de supuestos salvadores de la patria. 


\section{El Factor militar.}

La realización del Golpe de Estado requiere casi siempre la acción decidida de fuerzas militares o cuando menos la seria amenaza de su inminente empleo como instrumento de la violencia inherente a éste fenómeno político. En todo otro supuesto es ineludible la presencia activa o pasiva de contingentes militares o militarizados.

Esta decisiva gravitación y necesidad del factor militar, ha hecho decir que el Golpe de Estado sólo es posible ejecutarlo desde dentro del Poder mismo y por los jefes militares. Por otra parte, el Estado moderno se caracteriza por poseer un fuerte aparato militar y policial, dotado de elementos ofensivos y defensivos altamente desarrollados como consecuencia de una ciencia y una técnica muy evolucionada. Aún en casos de debilitamiento extremo de los órganos del Poder, como consecuencia de la guerra civil o extranjera, el Golpe de Estado está fuera del alcance exclusivo del elemento civil en un país moderno. Concretamente, el factor militar concurre a todo Golpe de Estado, ya sea este puro o incidental, cuando la violencia física es parte del proceso.

A veces actúa en beneficio de sus propios militares, otras apoyando con su fuerza a movimientos políticos de naturaleza civil. También es característico el control de los medios de comunicación, la prohibición de cualquier tipo de oposición y la suspensión del Estado de Derecho, al menos temporalmente.

\section{V.- TIPOS DE GOLPE DE ESTADO}

Existe una obra, publicada en 1931 por el italiano Curzio Malaparte, en la que se analizan exhaustivamente las formas de Golpe de Estado practicadas en la Historia. Se titula "Técnica del Colpo de Stato". El autor esclarece los distintos tipos de "Golpe de Estado" de la siguiente manera:

\section{A.- GOLPE DE ESTADO TÁCITO}

Son acciones de "cambio" más o menos revolucionario, ejecutadas desde el propio Gobierno, generalmente a instancias de los grupos de presión a los que se debe. 


\section{B.- GOLPE DE ESTADO TÉCNICO}

En apariencia la estructura institucional no cambia. Porque las Instituciones, aparentemente, siguen sosteniendo un régimen aparentemente democrático. Pero uno o varios grupos de presión, distintos a la Jefatura del Estado y del Ejecutivo, logran que éstos den forma legal a sus intereses y conveniencias. Frecuentemente se valen de la corrupción, incompetencia o debilidad de los que representan a las Instituciones del Estado. Suelen darse de la siguiente forma: subsisten las autoridades, el parlamento, el poder judicial y el sistema legal en general, pero por una acción de desacato de tipo extorsiva de un grupo poderoso (militares, grupos económicos, etc.) la autoridad legal se ve menoscabada, y ese grupo poderoso logra que las autoridades adopten ciertas decisiones que los favorecen.

\section{C.- GOLPE DE ESTADO ESPECULATIVO}

El que por medios económicos induce una crisis económica, o aprovecha la existente, para utilizar medios de presión que si no son satisfechos acaban causando procesos anárquicos y afectando la solidez y contenido del Estado de Derecho, utilizando la sumisión y el respaldo de subordinados vendidos a grupos de presión mediática.

\section{D.- GOLPE DE ESTADO INSTITUCIONAL}

Promovido por los que ostentan el Poder político y encaminado a una total remoción del sistema político, sin que ello suponga el desplazamiento del Poder de la autoridad que lo incita y desarrolla, ni de las instituciones que controla, aunque sí su debilitación de la capacidad operativa, como en el caso de un ejército que en pleno uso de su vigor, podría oponerse y limitar seriamente los propósitos y desmanes de los promotores del golpe.

Por su parte Félix Luna en "Historia Argentina: Gobiernos civiles y golpes militares".(1955), establece otro tipo de Golpe de la siguiente forma:

\section{A.- GOLPE DE ESTADO MILITAR}

Los golpes militares están determinados por el predominio de las Fuerzas Armadas por sobre las demás instituciones de gobierno. En tales circunstancias, el presidente es nombrado por los jefes de las Fuerzas Armadas y el Congreso 
reemplazado por las deliberaciones entre los mandos superiores de las distintas armas en la Junta de Comandantes. Las garantías constitucionales son suspendidas y las personas encontradas en actividades políticas son perseguidas como delincuentes. La Justicia y la Policía quedan supeditadas a las Fuerzas Armadas y el aparato burocrático del Estado continúa, con pocos cambios, sirviendo al nuevo régimen.

También es importante destacar la existencia de otra tipificación de Golpe de Estado como ser:

\section{A.-GOLPE DE ESTADO CONSTITUCIONAL}

Un Golpe de Estado constitucional es la toma del poder político, de un modo repentino y violento, por parte de un grupo de poder, defendiendo la legitimidad institucional establecida en un Estado, es decir, lo que indica la constitución vigente. Es cuando el Golpe de Estado está propiciado por quienes ya se encuentran en el poder, y solamente se produce un cambio de régimen político sin cambiar las autoridades que desde él ejercen el poder.

\section{VI.-SUCESIÓN CONSTITUCIONAL DEFINICIONES}

El derecho de sucesión es tan antiguo como la propiedad. Lo han admitido los pueblos de todas las civilizaciones, una vez salidos de las organizaciones primitivas de los clanes comunitarios. Este solo hecho bastaría para afirmar que se trata de una institución consustanciada con la naturaleza humana.

\section{A.- Sucesión (Terminología Común)}

La voz "sucesión" deriva del latin "succssion-onis y significa en sus tres primeros alcances: 1. Acción y efecto de suceder. Y esta última expresión deriva del Latín "succedere", significa a su turno.-Entrar una persona o cosa en lugar de otra persona o cosa, o seguirse de ella 3. . Sustitución de una persona por otra 4.- Prosecución, continuación ordenada de personas, cosas, sucesos, etc.

\section{B.-Sucesión (Concepto Jurídico, doctrina)}

Existen dos corrientes doctrinarias fundamentales que han estudiado sobre Sucesión: 
1.- Una que ve en la Sucesión toda adquisición derivada

2.- Otra que estima por sucesión tanto la adquisición derivada cuanto la adquisición originaria.

La primera teoría expresa que la adquisición de un derecho es originaria cuando ese derecho nace en cabeza del titular. Pero si el derecho adquirido existió antes en cabeza de otro titular, que lo transmite, se está ante una adquisición derivada.

La segunda teoría concuerda con la primera admitiendo la sucesión derivada pero expresa de sucesión originaria en la que innova. Dice que en este caso el derecho del sucesor subsiste por sí; sin derivar su fuerza del derecho del Predecesor ${ }^{12}$.

\section{C.- Sucesión en (Derecho Civil)}

Transmisión de derechos u obligaciones, por causa de muerte.

I.- La Corona. En las monarquías, al régimen implantado para sustituir al rey muerto, destronado, incapacitado o que abdica. En la totalidad de los actuales Estados monárquicos, con la excepción peculiar de la Santa Sede, la sucesión es hereditaria familiar.

II.- Título Universal. La que comprende la totalidad de un patrimonio o parte proporcional del mismo. La sucesión universal equivale a la herencia en sentido estricto; y el sucesor universal, al heredero por antonomasia.

Directa. Aquella en que la transmisión de bienes del causante al heredero se realiza sin interposición de otra persona.

Intestada. La transmisión, según normas legales, de los derechos y obligaciones del causante, por muerte del mismo o presunción de su fallecimiento, cuando no deja testamento, o éste resulta nulo o ineficaz.

Mortis Causa. La transmisión de los derechos y obligaciones de quien muere a alguna persona capaz y con derecho y voluntad de ejercer aquéllos y

${ }^{12}$ Enciclopedia Jurídica Omeba “Sucesión” Tomo XXV, pag 938, Buenos Aires Argentina, 1986. 
cumplir éstas.

Testamentaria o Testada. La que es deferida por manifestación de voluntad del causante, contenida en testamento válido, sea hecho por escrito o de palabra, en los supuestos excepcionales en que éste se admite.

Universal. La transmisión en un sentido general, efecto de suceder, seguir una persona a otra, continuarla en sus derechos y obligaciones.

III.- Más específicamente la sucesión ha sido definida como la transmisión de los derechos y obligaciones que componen la herencia de una persona muerta, a la persona que sobrevive, a la cual la ley o el testador Ilama para sucederla.

Esta definición permite extraer los elementos necesarios de toda sucesión mortis causa: 1) la persona fallecida, Ilamada también causante; 2) los Ilamados a sucederla, sea por la ley o por la voluntad del difunto. A estos se los designa con el nombre de sucesores o causahabientes; si la sucesión es a título particular, legatarios; 3) el conjunto de bienes de que era titular el difunto, es decir, un patrimonio en cabeza del causante. Se los designa bienes relictos.

Se puede afirmar que existe sucesión en todos los casos en el que el derecho adquirido deriva de otra persona, dependiendo postrero de la existencia del derecho anterior. Se entiende por tanto a la sucesión en dos sentidos: Sucesión mortis causa: Cuando una persona hereda de otra unos bienes por testamento o por disposición de la ley; Predomina tradicionalmente el uso de esta palabra en el enfoque mortis causa, la que se da tanto en sucesiones legítima (debido a la ley) como en la testamentaria (según testamento, contrato o capitulaciones). Siempre que se dé desde la muerte del autor de la sucesión o por la presunción legal de su muerte. Claramente nuestro Código Civil en su Artículo 930 establece "Se sucede a una persona difunta a titulo universal o a titulo singular". El diccionario y la doctrina establecen aspectos básicos para determinar la palabra Sucesión no definiendo específicamente "Sucesión Constitucional"

Verificando los conceptos tanto en el Diccionario de la Real Academia Española, la doctrina del Diccionario Jurídico y nuestro Código Civil podríamos deducir tres enfoques de Sucesión: 
1- Sustituir una persona por otra.

2- Al efecto de las Sucesiones por causa de muerte y sus derechos conexos.

3- A los efectos de la Sucesión en materia monárquica o eclesial.

El primer aspecto "Sustituir una persona por otra", es lógico con el simple entender que el Ex Presidente Manuel Zelaya Rosales fue sustituido por otra persona. Lo importante a definir es que si la persona que le sustituyo lo hizo de manera legal en el cargo.

Otra forma de suceder al Presidente pudo ser, que se hubiera ausentado de su territorio voluntariamente, por renuncia a su cargo, ser declarado en estado de incapacidad o demencia o mediante procedimiento legal tutelado como lo establecen las leyes hondureñas en caso de haberle deducido responsabilidad en la comisión de algún delito. Se encontró además, la utilización del término sucesión en el Código Penal en su Artículo 328 que se refiere a los delitos contra la Forma de Gobierno, en el numeral 4 establece como delito: "variar el orden legítimo de suceder a la Presidencia, o privar al sucesor del Presidente de las facultades que la constitución le otorga."

La segunda parte de la definición legal en nuestro Código, no es aplicable a lo sucedido con el Presidente Zelaya porque esto es estrictamente la parte de sucesiones de cuando la persona que sucede ha fallecido. Situación que no se dio.

Y el tercero, al ser nosotros una República, el efecto de la sucesión vinculado a una monarquía, no existe, por lo tanto no se realizará su análisis ${ }^{13}$.

\section{VII.- GOLPE DE ESTADO O SUCESIÓN EN HONDURAS (HECHOS)}

En los meses previos al 28 de junio, ocurría en nuestro país una crisis política entre los poderes de la República de Honduras, en el cual se enfrentaron el presidente Manuel Zelaya con el Presidente del Congreso Nacional Roberto Micheletti y la Corte Suprema de Justicia, sobre la legalidad de una consulta, la cual tenía como

\footnotetext{
${ }^{13}$ Hernández Alvarado, Carlos Augusto, "Análisis sobre Sucesión Constitucional”. Año 2009. carlosaugusto69@yahoo.com.
} 
objetivo inmediato saber si los hondureños estaban de acuerdo en que en los comicios de noviembre se colocase una llamada "Cuarta Urna" para votar un referéndum y cambiar la constitución por medio de una Asamblea Constituyente. El cambio de la Constitución se planteó supuestamente por la necesidad de revisarla totalmente en vista de sus contradicciones, por ser pétrea en varios artículos y no permitir la participación efectiva de los ciudadanos en los procesos de decisión y solución de los problemas locales y nacionales, y lo más importante era poder determinar que la Constitución no responde a la realidad nacional del siglo XXI, además de considerarse una mala copia de las constituciones de los años de 1865 y 1957. Para respaldar esa votación, presuntamente se recolectaron las firmas de 400 mil hondureños; la oposición sin embargo aseguró que las firmas fueron recogidas por extranjeros y funcionarios Públicos amenazados y afirmaban que el Presidente Manuel Zelaya buscaba con esta modificación a la Constitución, su reelección. La Corte Suprema de Justicia y el Tribunal Superior Electoral calificaron la consulta como ilegal, con base en una ley aprobada posteriormente a la realización de la convocatoria (cinco días antes de la celebración de la consulta) expresamente para prohibirla. A pesar de esas opiniones, el Presidente Zelaya mantuvo la consulta para el 28 de junio y ordenó al Ejército distribuir papeletas de votación, de conformidad con su papel en la realización de elecciones.

Después de que el jefe del Estado Mayor Conjunto, Romeo Vásquez Velásquez, se negase a obedecer esta orden, aduciendo una contraorden del Tribunal Supremo de Justicia, el presidente Zelaya anunció la destitución del cargo del jefe del ejército en un mensaje televisado, lo que provocó la renuncia de los jefes de las Fuerzas Armadas y la Fuerza Aérea. El 25 de junio, la Corte Suprema anuló la destitución del General Vásquez, mientras grupos militares tomaban la capital hondureña. Ese día, portavoces del presidente Zelaya anunciaron que el Presidente estaba a punto de nombrar el sustituto de Vásquez. Al día siguiente la situación en Honduras parecía más calmada, y los militares abandonaban Tegucigalpa en dirección a sus cuarteles, luego de que el General Vásquez se los ordenase. Por su parte, Zelaya declaró en una entrevista que en realidad no había destituido al General, solamente había anunciado su futura destitución.

Poco después, el Presidente Zelaya irrumpió en una base de la Fuerza Aérea donde se guardaba el material electoral que el General Vásquez se había negado a distribuir, retirándolo del lugar. De acuerdo a la Fuerza Aérea Hondureña, el Presidente de Venezuela, Hugo Chávez, envió este material a Honduras; pero 
Zelaya negó haber recibido financiamiento externo. El 26 de junio, la Corte Suprema, a pedido del Ministerio Público, aprobó por unanimidad de votos acusar como autor responsable al ciudadano José Manuel Zelaya, de los delitos de traición a la patria, abuso de autoridad y usurpación de funciones en perjuicio del Estado de Honduras; por lo cual dictó orden de captura y allanamiento contra el presidente. El mismo día, el juez José Tomas Arita Valle de la Corte Suprema de Justicia ordenó al teniente coronel René Antonio Herpburn Bueso del Estado Mayor Conjunto de las Fuerzas Armadas en allanar la vivienda del presidente Zelaya y ponerlo a orden de la justicia de Honduras por delitos en perjuicio del Estado ante el requerimiento del Ministerio Publico.

El 27 de junio, el día anterior a la votación, el Congreso designó una comisión especial para investigar a Zelaya, supuestamente "por desconocer los fallos de las instancias jurisdiccionales y violentar el Estado de Derecho". Solamente cuatro diputados izquierdistas se opusieron a la moción de la Asamblea. Los principales grupos los distintos partidos políticos diputados miembros del Congreso Nacional habían acusado a Manuel Zelaya de violar la constitución. De esta manera, al final del día, la Fiscalía General, la Corte Suprema de Justicia y el Congreso de la República se habían unido a la opinión del Tribunal Supremo Electoral, declarando ilegal la consulta.El propio partido de Zelaya, el Partido Liberal de Honduras, manifestó también su oposición a la controversial consulta. Y el decreto ejecutivo que ordenaba el referéndum fue derogado por el Juzgado de Letras de lo Contencioso Administrativo pues declaró "ilegal e inconstitucional el solo hecho de insinuar el Ilamado a una Constituyente".

En la mañana del 28 de junio, Fuerzas Armadas al mando del teniente coronel René Antonio Herpburn Bueso allanaron la residencia presidencial deteniendo en el acto al presidente Manuel Zelaya luego, fue trasladado a la Base de la Fuerza Aérea al sur de Tegucigalpa expulsándolo del territorio hondureño para ser Ilevado a Costa Rica. En sesión del Congreso Nacional de Honduras se admitió la renuncia del presidente Zelaya por una supuesta carta que habría redactado el mismo el 25 de junio antes de su expulsión. Desde Costa Rica el presidente Zelaya desmintió haber presentado tal renuncia e hizo un Ilamado a la desobediencia civil. Luego, el Congreso resolvió por unanimidad la destitución del presidente Zelaya, por considerar que las acciones de gobierno de éste habían violado la Constitución y el ordenamiento jurídico del país, y designó para sucederlo al presidente del Congreso, Roberto Micheletti, con el compromiso de 
que el mismo permanecería en el cargo hasta la terminación del mandato de Zelaya en enero de 2010. La Constitución dicta que ante la ausencia del Presidente del Ejecutivo, el Presidente del Congreso Nacional, asuma las funciones de jefe de Estado de forma provisional. Las Fuerzas Armadas Hondureñas desplegaron un dispositivo preventivo con varios aviones de combate y con soldados en las calles de Tegucigalpa, donde la policía lanzó gases lacrimógenos contra simpatizantes de Zelaya que se manifestaban en el centro de la ciudad. Cortaron los servicios electricidad, telefonía, cable e Internet del país.

Micheletti decreta el toque de queda por 48 horas con posibilidad de ampliación, mientras sucedían las protestas. Otra de las medidas tomadas fue la prohibición de trasmisiones de cadenas internacionales dentro de Honduras. También fueron detenidos por fuerzas militares varios periodistas, quienes posteriormente fueron puestos en libertad. También se denuncia que las tropas secuestraron a los embajadores de Cuba, Nicaragua y Venezuela y la canciller hondureña Patricia Rodas. Según algunas de las instituciones hondureñas se trata de un evento de iure (una orden judicial) y una sucesión presidencial legítima; según los organismos de la comunidad internacional se trata de una situación de facto (un Golpe de Estado) por lo que no ha sido reconocido por ningún país. La comunidad internacional, incluyendo a las Naciones Unidas, la Organización de Estados Americanos y la Unión Europea, se pronunciaron en contra de este evento, calificándolo como una "ruptura del orden constitucional" y exigieron unánimemente la restitución del expresidente Manuel Zelaya en sus funciones.

En las semanas posteriores al 28 de junio, el Congreso decretó un estado de sitio, suspendiendo garantías de los ciudadanos contenidas en 8 artículos de la constitución, hubo movilizaciones en apoyo de ambos sectores, una de las cuales desembocó en el asesinato de un manifestante opositor al golpe, la OEA suspendió a Honduras como miembro de la organización hasta que el país "restaurara el gobierno democrático" (el de Manuel Zelaya), El Salvador, Nicaragua, Guatemala, Venezuela y los Estados Unidos anunciaron sanciones económicas para Honduras a causa del "Golpe de Estado", el BID y el Banco Mundial anunciaron la suspensión de la ayuda financiera que otorgaban a Honduras y se produjo una retirada en bloque de todos los embajadores de la Unión Europea de Honduras. Tras la realización de las elecciones presidenciales hondureñas el 29 de noviembre de 2009 donde resultó victorioso Porfirio Lobo Sosa del Partido Nacional de Honduras, Estados Unidos y diferentes países 
latinoamericanos con gobiernos de tendencia derechista como Colombia, Costa Rica y Perú aseguraron que reconocerían el nuevo gobierno, mientras que países latinoamericanos con gobiernos izquierdistas como Argentina, Brasil, Ecuador y Venezuela anunciaron que seguirían sin reconocer el nuevo gobierno post-golpista por considerarlo ilegítimo.

Honduras fue suspendida de la Organización de Estados Americanos, debido a que el presidente interino Roberto Micheletti rechazó el ultimátum que este organismo le concedió para que abandonara la presidencia y se restableciera el anterior gobierno. Aunque José Miguel Insulza, secretario general de la OEA aseguró que estaba abierto al diálogo con la nueva administración hondureña ${ }^{14}$.

\section{VIII.- ANÁLISIS LEGAL Y OPINIÓN DE LO ACONTECIDO EN HONDURAS}

A continuación se hará un análisis de algunos artículos que forman parte fundamental en lo acontecido en los meses anteriores y posteriores al 28 de junio del 2009, tomaremos como base la Carta Magna, exponiendo detalladamente el articulo y analizándolo con los hechos ocurridos.

\section{A.- Constitución de la República de Honduras}

Nuestra Constitución de la República en su articulado establece una serie de Garantías, Derechos y Deberes que pertenecen a todo ciudadano hondureño los cuales deben ser fielmente respetados y cumplidos. Entre ellos podemos mencionar que la persona humana es el fin supremo de la Sociedad y del Estado. Todos tienen la obligación de respetarla y protegerla. Establece además que la dignidad del ser es inviolable y toda persona tiene derecho a que se respete su integridad física, psíquica y moral. Nadie debe ser sometido a torturas, ni penas o tratos crueles, inhumanos o degradantes, y no se aplicarán leyes y disposiciones gubernativas o de cualquier otro orden, que regulen el ejercicio de las declaraciones, derechos y garantías establecidos en esta Constitución, si los disminuyen, restringen o tergiversan ${ }^{15}$.

\footnotetext{
${ }^{14}$ http://es.wikipedia.org/wiki/Golpe_de_Estado_en_Honduras_de_2009

${ }^{15}$ Ver Artículos 59, 64, 68,69 de la Constitución de la República
} 
Existen además en nuestra Constitución artículos sobre el debido proceso para someter a cualquier persona a las órdenes de los juzgados así como el derecho que se tiene a la Defensa, entre ellos tenemos: El artículo 69 que reza: "La libertad personal es inviolable y sólo con arreglo a las leyes podrá ser restringida o suspendida temporalmente". El Art.71 "Ninguna persona puede ser detenida ni incomunicada por más de veinticuatro horas, sin ser puesta a la orden de autoridad competente para su juzgamiento". Art 82 "El derecho de defensa es inviolable". El Art.89 "Toda persona es inocente mientras no se haya declarado su responsabilidad por autoridad competente. Art 90 "Nadie puede ser juzgado sino por juez o tribunal competente con las formalidades, derechos y garantías que la Ley establece". Art.98 "Ninguna persona podrá ser detenida, arrestada o presa por obligaciones que no provengan de delito o falta". Art.102 "Ningún hondureño podrá ser expatriado ni entregado por las autoridades a un Estado extranjero".

En el caso que nos ocupa, el señor Manuel Zelaya no solo como ciudadano hondureño, sino como representante y máxima autoridad de Honduras, fue sujeto de una clara violación a los derechos y garantías que defiende la constitución, fue irrespetada su integridad física, psíquica y moral, y fue expulsado de manera degradante a Costa Rica, el derecho de Defensa fue violado, así como al debido proceso. Se conoce que en nuestro país, existen esfuerzos, sin claros resultados para que exista Seguridad Jurídica, y en vista de que las leyes se aplican o interpretan a conveniencia de los grupos de poder, irrespetando completamente el espíritu por el cual fueron creadas, podemos expresar que tanto las actuaciones de la Corte Suprema de Justicia, el Poder Legislativo, el Ministerio Público ${ }^{16}$, y las Fuerza Armadas en cuanto a quien ejercía la Titularidad de la Presidencia en ese momento, no fueron con base al procedimiento legal establecido; el miedo, y la incertidumbre de estas instituciones con respecto a la cuarta urna, provoco una actuación precipitada e ilegal.

...."La suplantación de la soberanía popular y la usurpación de los poderes constituidos se tipifican como delitos de traición a la Patria. La responsabilidad en estos casos es imprescriptible y podrá ser deducida de oficio o a petición de

${ }^{16}$ Considerando de la Ley del Ministerio Publico "Que con el objeto de impartir justicia con independencia, imparcialidad y legalidad, de modo práctico y eficaz, es procedente la emisión de la Ley del Ministerio Público, organismo que asumirá la obligación ineludible de la investigación de los delitos y el ejercicio de la acción penal pública, la vigilancia en el cumplimiento exacto de las condenas, así como la sujeción estricta del órgano jurisdiccional a la Constitución de la República y las leyes, con la potestad de iniciar los procedimientos para el enjuiciamiento de funcionarios infractores del orden jurídico". 
cualquier ciudadano". Art.2. El Congreso Nacional y su presidente Roberto Micheletti usurparon al Poder Ejecutivo y sus funciones, y por lo tanto incurrieron en delito. Inventaron una falacia, que fue la supuesta carta del ex presidente Zelaya renunciando a su cargo, en la que en sesión ordinaria dieron por aceptada, utilizando en el mismo acto como lapsus el artículo 242 de fundamento para la aplicación del término sustitución constitucional. La actuación del Congreso Nacional en este aspecto fue un acto circense. El artículo en mención expresaba "En las ausencias temporales del Presidente de la República lo sustituirá en sus funciones el Vicepresidente, si la falta del Presidente fuere absoluta, el Vicepresidente ejercerá la titularidad del Poder Ejecutivo por el tiempo que falte para terminar el periodo constitucional. Pero si también faltare de modo absoluto el Vicepresidente de la República, el Poder Ejecutivo será ejercido por el Presidente del Congreso Nacional y, a falta de éste por el Presidente de la Corte Suprema de Justicia, por el tiempo que faltare para terminar el periodo presidencial... ${ }^{17}$.

Uno de los artículos más polémicos durante la crisis que sufrió el país fue el Artículo 239 Constitucional que establece: "El ciudadano que haya desempeñado la titularidad del Poder Ejecutivo no podrá ser Designado o Presidente. El que quebrante esta disposición o proponga su reforma, así como aquellos que lo apoyen directa o indirectamente, cesarán de inmediato en el desempeño de sus respectivos cargos, y quedarán inhabilitados por diez (10) años para el ejercicio de toda función pública.."

Mientras que el Código Penal en su Artículo 330 expresa "Será sancionado con reclusión de seis a diez años quien habiendo ejercido a cualquier título la Presidencia de la República, promoviere o ejecutare actos Violatorios del Artículo constitucional que le prohíbe ejercer nuevamente la Presidencia de la República o desempeñar de nuevo dicho cargo bajo cualquier Título.

En la misma pena incurrirán quienes lo apoyaren directamente o propusieren reformar dicho artículo. Cuando los autores de esos delitos fueren funcionarios serán sancionados además con inhabilitación absoluta por diez años contados desde la fecha de la violación o de su intento de reforma.

17 Al artículo 242 se le han realizado varias reformas y actualmente fue reformado y menciona designados presidenciales. Por el Recurso de Inconstitucionalidad N. 514-08 
El artículo que antecede claramente se establece que está prohibido intentar cualquier tipo de reforma a la reelección de la Presidencia y las consecuencias de ello serán:

a.- Cese Inmediato en el desempeño de sus cargos.

b.- Inhabilitación por 10 años para el ejercicio de toda función pública.

El Código Penal nos establece la sanción por este delito que será de 6 a 10 años y la inhabilitación absoluta contados desde la fecha de la violación o su intento. Las actuaciones del ex presidente Zelaya y la de sus asesores daban mucho que pensar y solo ellos sabrán cuales eran sus intereses, en vista que solo tendríamos hipótesis sin comprobar, si realmente las intenciones de la consulta eran para favorecer a la ciudadanía y ajustar la nueva constitución a los cambios del siglo 21 o si buscaba definitivamente una reelección y permanecer en el Poder.

Aunque si analizamos las constituciones pasadas de los años de $1865^{18}$ y $1957^{19}$ según las cuales los promotores de una Asamblea Nacional Constituyente, expresaban que la Constitución de 1982 "es una copia que hay que cambiar de las constituciones mencionadas anteriormente", vemos, específicamente en la reelección del presidente que las dos tienen en común la prohibición terminante de la reelección presidencial. En todo caso si sus intenciones eran la Reelección sin duda alguna que debía ser sometido a investigación por parte del Ministerio Publico y aplicársele claramente lo que establecen las leyes procesales tanto administrativa, civil y penalmente, debiendo ser sometido ante la Corte Suprema de Justicia a través del Juzgado de lo Penal como el órgano facultado para juzgar a los infractores de la ley. Hago un paréntesis en la investigación y analizando el artículo 240 de quienes no pueden ser elegidos presidentes ni designados presidenciales analizo que este articulo ha sufrido reformas a conveniencia de los políticos de turno, como es posible que siendo un artículo

${ }^{18}$ Constitución de 1865 de la República de Honduras ARTíCULO 33 "El período presidencial será de cuatro años, sin lugar a reelección sucesiva. Comienza el 1 de febrero del año de la renovación".

${ }^{19}$ Constitución de 1957 de la República de Honduras Artículo 4.- La alternabilidad en el ejercicio de la Presidencia de la República es obligatoria. La violación de esta norma da derecho a la insurrección popular. Artículo 196.- El ciudadano que haya desempeñado a cualquier título la Presidencia de la República, no podrá ser Presidente 0 Designado en el periodo presidencial siguiente. Artículo 197.- El funcionario que viole el Artículo anterior o que proponga reformarlo, y los que lo apoyen directa o indirectamente, cesarán de inmediato en el desempeño de sus respectivos cargos y quedarán inhabilitados para el ejercicio de toda función pública. 
se encuentra redactado, los pasados, presentes y talvez futuros Presidentes del Congreso Nacional, de la Corte Suprema de Justicia, de los partidos tanto liberal como nacional , así como los Secretarios de Estado, ostentan la Presidencia de la República sin inmutarse y desde sus puestos como servidores de la patria, realicen campañas aprovechándose del cargo que fungen. Estas personas son infractores de la Constitución de la República, conspiran contra la nación, cometen abuso de autoridad y violan los deberes de los funcionarios, en este tipo de situaciones es evidente la impunidad y corrupción.

\section{CONCLUSIONES}

No existe en nuestro Derecho Positivo vigente ninguna Ley, que defina o conceptualice el termino Golpe de Estado o Sucesión Constitucional, por lo tanto existe un vacío legal en cuando a la regulación de esta figura, por ende la Investigación se apoyó de la doctrina como fuente inevitable de investigación en el campo Jurídico y se lograron las siguientes conclusiones:

- Al realizar el análisis doctrinario de la figura de Golpe de Estado podemos concluir claramente que lo acontecido el 28 de junio del 2009 en la República de Honduras fue un evidente Golpe de Estado ya que las características específicas de esta figura como ser la expulsión de las autoridad, la intervención de las fuerzas militares y el uso de la violencia, se manifestaron concretamente con la Expulsión del Presidente en funciones a la ciudad de San José, Costa Rica; realizada de manera violenta por el allanamiento de la que fue objeto la residencia del presidente por parte de las Fuerzas Armadas. Resultando consecuentemente con ello, el control de los medios de comunicación, la prohibición de cualquier tipo de oposición y la suspensión del Estado de derecho.

- El primer término que utilizaron los promotores del Golpe de Estado fue Sustitución Constitucional, enfatizo fue Sustitución Constitucional basándose en el artículo 242 actualmente reformado de la Constitución que se refiere a las ausencias temporales del Presidente y expresa claramente quien sustituirá al Presidente y ejercerá la titularidad del Poder Ejecutivo, mencionando en primer lugar al Vicepresidente de la República que en ese momento no existía por haber interpuesto su renuncia, y en caso que este faltare el titular seria el Congreso Nacional y en su defecto la Corte Suprema de Justicia. Para la aplicación de este 
artículo tomaron como base la supuesta carta de renuncia del Ex presidente Zelaya en la que hubo un clarísimo delito de falsificación de documento y la referida ausencia que fue ilegalmente provocada por las fuerzas militares. La utilización del término Sucesión Constitucional en concreto, doctrinariamente no se encontró, solo pudimos analizar la palabra Sucesión que como vimos en su definición es la Acción y efecto de suceder, entrar en lugar de otra o de Sustituir a una persona por otra.

- Legalmente hablando lo que se regula de Sucesiones en nuestra legislación es en los artículos del 930 en adelante del Código Civil sobre la sucesión por causa de muerte por lo tanto no es aplicable en vista que el ex presidente Manuel Zelaya no murió por lo tanto no se podía suceder la titularidad de la Presidencia.

- Ahora si nos plateáramos como hipótesis que, si en efecto se siguió el procedimiento legal para sustituir al Ex presidente Zelaya siempre estaríamos ante un Golpe de Estado pero denominándolo Golpe de Estado Constitucional que como expresamos en la Investigación es la toma del poder político, de un modo repentino y violento, por parte de un grupo de poder, defendiendo la legitimidad institucional establecida en un Estado, es decir, lo que indica la constitución vigente.

\section{RECOMENDACIONES}

- Se recomienda tipificar la Figura Golpe de Estado en el Código Penal y a las presentes y futuras autoridades respetar todo el ordenamiento jurídico de nuestro país, especialmente la Constitución de la República.

- La regulación de una revocatoria del mandato, plebiscito revocatorio o referéndum revocatorio como un procedimiento a través del cual los electores, pueden destituir al presidente de su cargo, con anterioridad a la expiración del período para el cual fue elegido, podría ser una solución de la ciudadanía al no estar satisfechos con el gobierno. 


\section{BIBLIOGRAFÍA}

Canal Social. Enciclopedia. Política.

http://www.canalsocial.net/enciclopedia/enciclopedia.asp. S. Sánchez González. Editorial Rialp. Gran Enciclopedia Rialp, 1991.

Diccionario Anaya de la Lengua.

Diccionario Ideológico de la Lengua española, Julio Casares de la Real Academia Española.

Editorial Gustavo Gili S.A.- Barcelona, 1985.

Enciclopedia Jurídica Omeba "Golpe de Estado" Tomo XIII, pag 350, Buenos Aires Argentina, 1986.

Enciclopedia Jurídica Omeba "Sucesión" Tomo XXV, pag. 938, Buenos Aires Argentina, 1986

"Golpe de Estado" Enciclopedia Microsoft ${ }^{\circledR}$ Encarta $^{\circledR}$ en línea 2002 http://encarta.msn.es ${ }^{\odot}$ 1997-2002 Microsoft Corporation.

Hernández Alvarado, Carlos Augusto, "Análisis sobre Sucesión Constitucional. carlosaugusto69@yahoo.com Año 2009.

Moliner, María. “Diccionario de uso del español "A-G, Editorial Gredos S.A. Madrid, 1997.

Orellana Ángel Edmundo "Documentos de Análisis Artículos sobre el Golpe de Estado en Honduras" Boletín Especial \#93 Centro de Documentación de Honduras CEDOH, Septiembre 2009.

Salomón Leticia, Manuel Calderón. "Documentos de Análisis"Artículos sobre el

Golpe de Estado en Honduras Boletín Especial \#92 Centro de Documentación de Honduras. CEDOH, Septiembre 2009.

Segundo V. Linares Quintana. "Tratado de la ciencia del Derecho constitucional" T. 6 Buenos Aires 1956, pág. 254.

http://porhonduraslibre.blogspot.com.

http://es.wikipedia.org/wiki/Golpe_de_Estado_en_Honduras_de_2009.

\section{LEGISLACIÓN}

- Código Civil de Honduras 1906.

- Código Penal de Honduras Decreto N 144-83.

- Constitución de la República de Honduras 1982.

- Ley del Ministerio Público. Decreto Número 228-93. Honduras.

- Reglamento de Organización, Funcionamiento y Competencias del Poder Ejecutivo. Honduras. Año 1997. 